\title{
Anatomic variations of coronary arteries: origins, branching patterns, and abnormalities
}

\author{
Natatcha Khwansang, Vilai Chentanez*
}

\begin{abstract}
Background: Anatomic variations in orifices, courses, branching patterns, and abnormalities of coronary arteries could affect blood supply, hemodynamic characteristics, and clinical symptoms, and could be a risk of atherosclerosis.

Objectives: To investigate the location and number of both coronary orifices in the aortic cusps, branching patterns of left main trunk, dominant pattern of posterior interventricular artery (PIA), prevalence of right posterior diagonal artery (RPDA), myocardial bridge, and other abnormalities.

Methods: We dissected 95 heart specimens from cadavers of Thai donors without the history of surgery, and the dominant patterns, location and number of orifices in the aortic cusps, branching patterns, origin and number of conal arteries, and occurrence of RPDA were determined.

Results: Dual aortic origin of the coronary orifice was the most common condition. Anomalous 2 orifices in the left aortic cusp were found in one specimen in which the right coronary artery (RCA) arose from aortic cusp and had an interarterial course. Right dominance and trifurcated form of left main trunk were found more frequently. Most frequently 2 conal arteries were found. RPDA was found in $45 \%$ and mostly originated from RCA. The prevalence of myocardial bridge was $62 \%$ and located mostly on the anterior interventricular artery (AIA).

Conclusions: The prevalence of right dominance, RPDA, the atypical origin of RCA from the left sinus, and the prevalence of myocardial bridges was more frequent than reported by others, whereas the dual aortic origin from both cusps and the prevalence of bifurcated left main trunk was less frequent.
\end{abstract}

Keywords: anatomy; arteries; cardiovascular diseases; coronary vessels; coronary vessel anomalies; myocardial bridging

The number of patients with cardiovascular disease has increased every year. Cardiovascular diseases are a leading cause of death worldwide [1]. In Thailand, the incidence of ischemic heart disease has increased every year [2]. Knowledge of anatomical pattern, variations, and anomalies of coronary arteries is important for the proper interpretation of coronary angiographies and revascularization procedures.
The left coronary artery (LCA) and right coronary artery (RCA) originate from their own aortic cusps. The left coronary artery (LCA) continues into the coronary sulcus. It is also known as left main trunk before bifurcating into anterior interventricular artery (AIA) and circumflex artery (CxA). The additional branch that can be found between 2 arteries as a variation is the median artery (MA). The RCA it, travels down the coronary sulcus and gives off the sinoatrial node artery.

\footnotetext{
*Correspondence to: Vilai Chentanez, Department of Anatomy, Faculty of Medicine, Chulalongkorn University, Bangkok 10330, Thailand, e-mail: vilai.ch@chula.ac.th

Department of Anatomy, Faculty of Medicine, Chulalongkorn University, Bangkok 10330, Thailand
}

כ Open Access. (c) 2018 Khwansang and Chentanez, published by Sciendo. (cc))BY-NC-ND This work is licensed under the Creative Commons Attribution NonCommercial-NoDerivatives 4.0 License. 
However, the conal artery can be noticed as a variation near its origin. The RCA might give off the right posterior diagonal artery (RPDA) as a variation before it continues to the posterior interventricular sulcus as the posterior interventricular artery (PIA).

Anatomic variations in orifices, courses, branching patterns, and abnormalities of coronary arteries, which have been reported in previous studies could affect blood supply, hemodynamic characteristics, and clinical symptoms and could be a risk of atherosclerosis [3]. However, various populations in those studies lead to varieties of coronary artery information. To our knowledge, there is no cadaveric report of the anatomic variation in the Thai population. This descriptive study intended to investigate the location and number of both coronary orifices in the aortic cusps, branching patterns of coronary arteries, dominant pattern, prevalence of RPDA, myocardial bridge, and others abnormalities in the Thai population. The expected benefit is to provide a database of coronary arteries for coronary angiography.

\section{Methods}

After this cadaveric study was approved by the institutional review board (IRB) of the Faculty of Medicine, Chulalongkorn University (IRB No. 667/60, approval No. 044/2017), 95 heart specimens from cadaver donors without a history of heart surgery (48 male, 47 female) from the Department of Anatomy, Faculty of Medicine, Chulalongkorn University, were collected and preserved in $10 \%$ formalin. After dissection, the dominant patterns were determined by observing the origin of the PIA. The PIA originated from RCA was classified as right dominance. PIA from $\mathrm{CxA}$ was classified as left dominance, and if the PIA arose from both arteries it would be classified as codominance [4]. We identified the location and number of orifices in the aortic cusps, branching patterns of the LCA, origin and number of conal arteries from the RCA, the occurrence of RPDA and its origin.

Abnormalities of coronary arteries were classified according to Angelini et al. as abnormality of origins and courses [5]. All data are presented as percentages after analyses using IBM SPSS Statistics for Windows (version 21).

\section{Results}

The study included 95 heart specimens (mean age of donors at death \pm standard deviation, $76.9 \pm 13.2$ years; range 34-99 years) with 48 male $(78.0 \pm 11.7$ years; range 41-99 years) and 47 female $(75.8 \pm 14.6$ years; range 34-96 years).

The prevalence of normal coronary artery variations is summarized in Table 1. The right dominance was the most common type of the coronary arterial system. The left and codominant patterns were found in $5 \%$ and $2 \%$, respectively (Figure 1). One coronary orifice in each aortic cusp (dual aortic origin) was the most common. The most frequent variation was one in the left aortic cusp and 2 in the right aortic cusp. The extra orifice in the right cusp was noted as the origin of the conal artery (Figure 2).

The data of branching patterns of the LCA were collected from 93 specimens, because 2 were incomplete due to student dissection. The left main trunk normally bifurcated into AIA and CxA in 32 cases (34\%). The most common

Table 1. Anatomic variations of coronary arteries, $\mathrm{n}(\%)$

\begin{tabular}{|c|c|}
\hline \multicolumn{2}{|l|}{ Dominant pattern $(n=95)$} \\
\hline Right & $88(93)$ \\
\hline Left & $5(5)$ \\
\hline Codominance & $2(2)$ \\
\hline \multicolumn{2}{|l|}{ Coronary orifices $(n=95)$} \\
\hline Dual aortic origin & $65(68)$ \\
\hline One orifice in the left and 2 orifices in the right aortic cusps & $28(29)$ \\
\hline One orifice in the left and 3 orifices in the right aortic cusps & $1(1)$ \\
\hline Two orifices in the left aortic cusp & $1(1)$ \\
\hline \multicolumn{2}{|l|}{ Branching pattern of LCA $(n=93)$} \\
\hline Bifurcation & $32(34)$ \\
\hline Trifurcation & $53(57)$ \\
\hline Quadrifurcation & $8(9)$ \\
\hline \multicolumn{2}{|l|}{ Conal artery $(n=95)$} \\
\hline One branch & $31(33)$ \\
\hline With a separate orifice & $7(7)$ \\
\hline From RCA & $24(25)$ \\
\hline Two branches & $53(56)$ \\
\hline Two with separate orifices & $1(1)$ \\
\hline One separate orifice and one RCA & $17(18)$ \\
\hline From RCA & $35(37)$ \\
\hline Three branches & $11(12)$ \\
\hline One separate orifice and 2 RCAs & $4(4)$ \\
\hline From RCA & $7(7)$ \\
\hline \multicolumn{2}{|l|}{ RPDA $(n=95)$} \\
\hline Absence & $52(55)$ \\
\hline From RCA & $43(45)$ \\
\hline
\end{tabular}

LCA, left coronary artery; RCA, right coronary artery; RPDA, right posterior diagonal artery 

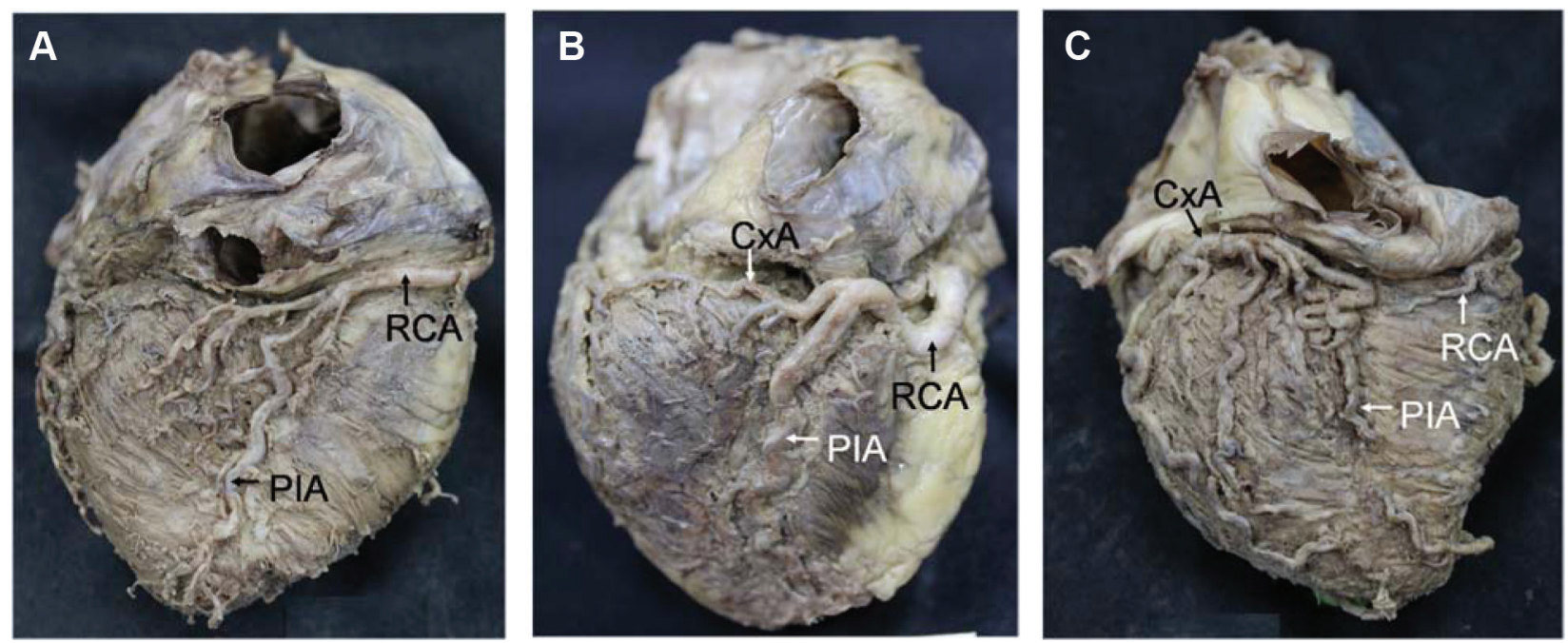

Figure 1. (A) Right dominance. (B) Codominance. (C) Left dominance.

CXA, circumflex artery; PIA, posterior interventricular artery; RCA, right coronary artery
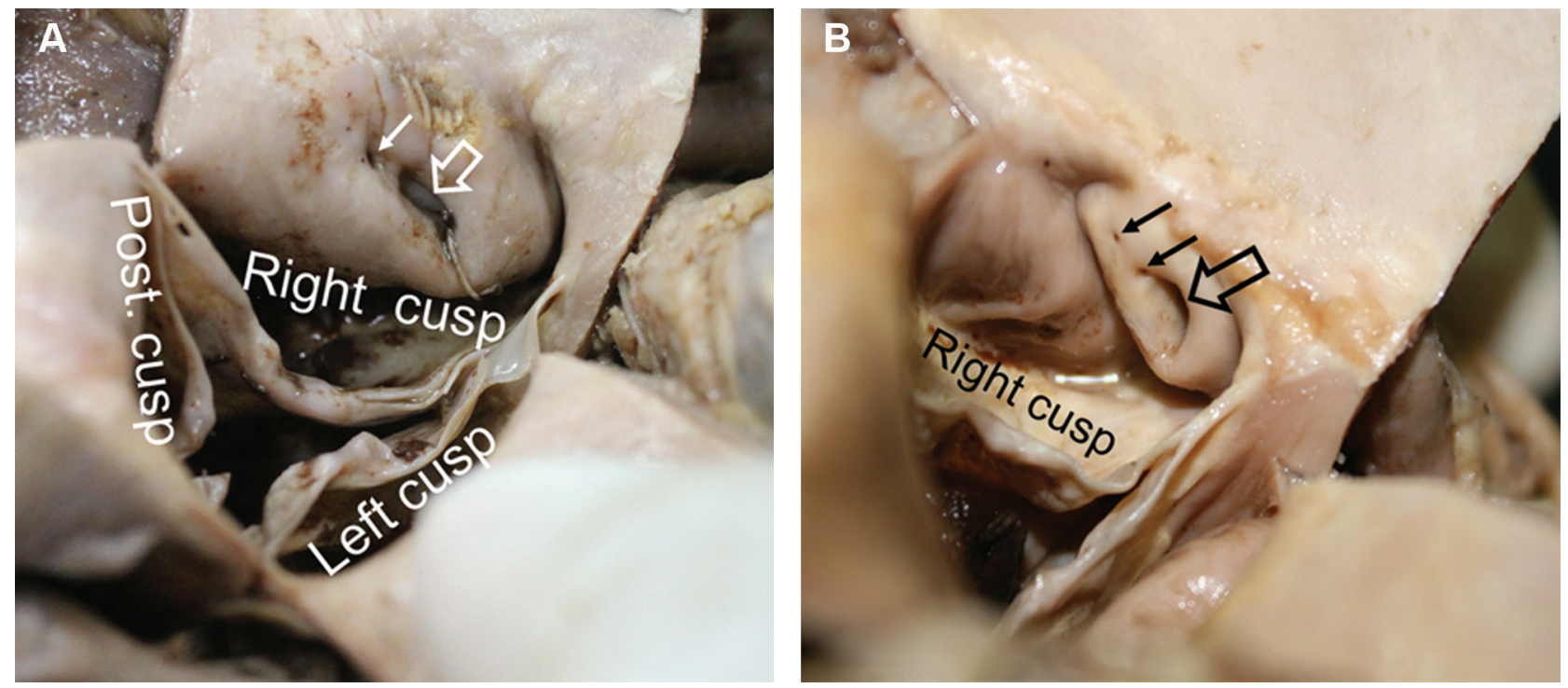

Figure 2. (A) Two orifices in the right cusp. (B) Three orifices in the right cusp. Extra orifice (arrow) aside from RCA (open arrow) was conal artery. RCA, right coronary artery

type was trifurcation. MA was the additional branch. In all specimens, the first branch of the RCA was the conal artery. This artery most frequently had 2 branches $(56 \%)$ and most branches originated from the RCA (Table 1; Figure 3).

The RPDA was found in 43 specimens (45\%). All RPDAs arose from the RCA after giving the right marginal artery. In 3 specimens, RPDA branched from the RCA at the acute margin of the right ventricle (Figure 4). Most of the RPDA occurred in a right dominant pattern. The prevalence of abnormalities of coronary arteries including the anomalous origin of RCA from the left aortic cusp (Figure 5A), and the myocardial bridge are summarized in Table 2. The RCA in this anomalous case coursed interarterially between the aorta and the pulmonary trunk to continue into the coronary sulcus (Figure 5B).

A myocardial bridge was found in 62\% (59 of 95 specimens). Most bridges comprised ventricular myocardium except one that was the right atrial wall (Figure 6). In these cases, after giving the right marginal artery, the RCA traveled into the right atrium wall above the coronary sulcus and emerged from the atrial wall to terminate in the right ventricle before reaching the posterior interventricular sulcus. The PIA, in this case, was derived from the CxA. The number of myocardial bridges in each specimen ranged from 1 to 4 . The most 

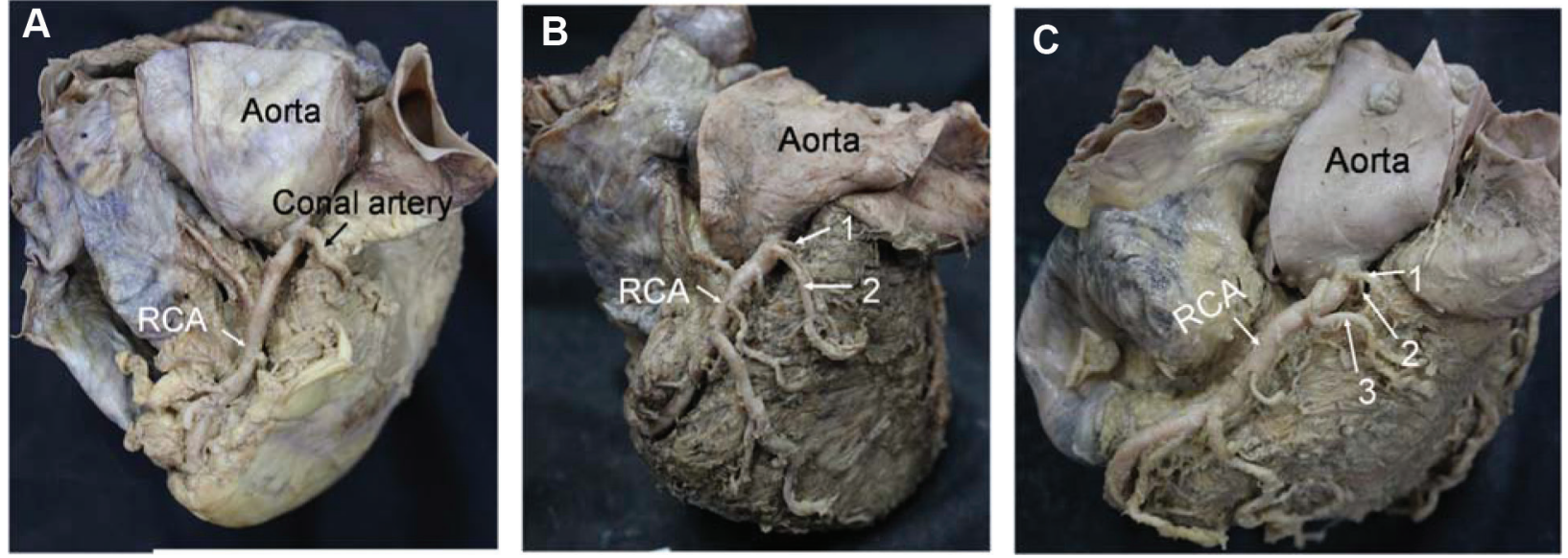

Figure 3. (A) One conal artery from the aorta. (B) Two conal arteries, one from aorta (1) and another from RCA (2). (C) Three conal arteries, one from aorta (2), 2 from RCA $(1,3)$.

$\mathrm{RCA}$, right coronary artery
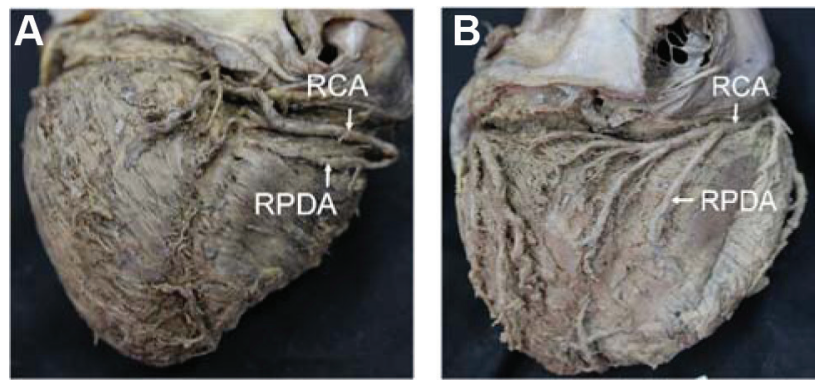

Figure 4. (A) RPDA branched from RCA at acute margin; (B) RPDA branched from RCA after giving the marginal artery. $\mathrm{RCA}$, right coronary artery; RPDA, right posterior diagonal artery

common location of the myocardial bridge was situated at the AIA. The locations and number of myocardial bridges are shown in Table 2 and Figure 7.

\section{Discussion}

Identification of the dominant pattern of coronary arteries has clinical importance particularly from the functional impact of myocardial ischemia [3]. The prevalence of right dominance had been reported to be $40 \%-80 \%$ [3, 6-8], left dominance $6.8 \%-18.57 \%[7,9,10]$, and codominance $10 \%-42.5 \%[8,11$, 12]. In the present study, the prevalence of right dominance was slightly higher than that reported previously, but left and codominance were considered to be lower. However, the codominant type was reported to be absent [6]. The inconsistency could be explained by the definition of the codominant type [7]. Moreover, dissection might not always yield the same result as radiology when evaluating the anatomy of the coronary artery [3].
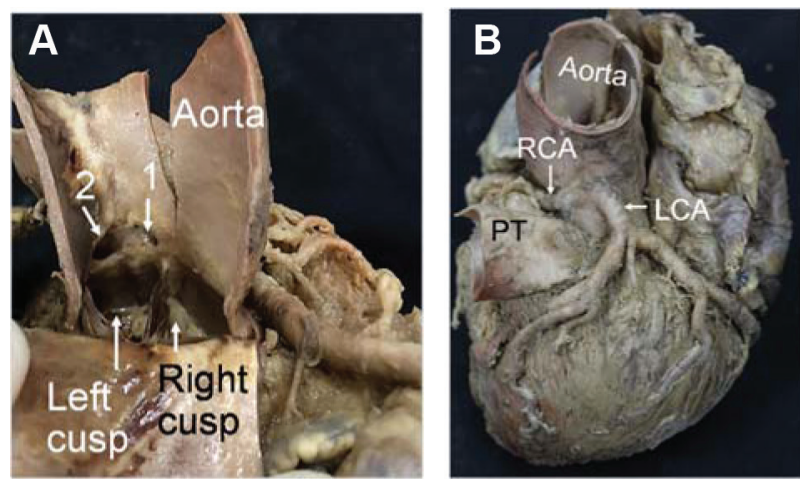

Figure 5. (A) Two orifices in the left aortic cusp: RCA (1) and LCA (2). (B) Interatrial course of RCA between PT and aorta.

$\mathrm{LCA}$, left coronary artery; PT, pulmonary trunk; RCA, right coronary artery

In $94.7 \%-100 \%$, the 2 coronary orifices were typically located in both aortic cusps $[3,13,14]$. However, additional orifices can be found in the right aortic cusp. Most of these orifices belonged to conal arteries in 33\%-51\% [15], and some of them belonged to the sinoatrial node artery $(0.4 \%)$ [7]. The prevalence of 2 and 3 orifices in the right aortic cusp was $22 \%-28.81 \%$ and $0.2 \%$, respectively [7, 10]. In the present study, there was a lower prevalence of dual aortic origin, whereas the prevalence of 2 orifices within the right cusp was similar to that reported previously [7, 10]. Moreover, the occurrence of 3 orifices in the right cusp was higher [7]. The presence of multiple orifices might cause problem and should be considered while performing the right ventriculotomy [7].

Left main trunk bifurcated into the AIA and the $\mathrm{CxA}$ in $50 \%-93.3 \%[6,11,16]$. Eventually, the trunk might be terminated by trifurcation in $6.7 \%-46 \%[5,10,15]$ and quadrifurcation in $4 \%-10 \%[6,8,11]$. In the present study, the prevalence of bifurcation was lower. Conversely, there were high percentages 
Table 2. Prevalence of coronary artery anomalies, $n(\%)$

\begin{tabular}{lr}
\hline Anomalous origin of RCA & \\
RCA from the left aortic cusp & $1(1)$ \\
Myocardial bridge & $42(44)$ \\
One site & 3 \\
AIA & 2 \\
RPDA & 2 \\
PIA & 1 \\
LMA & $112)$ \\
Two sites & 5 \\
AIA/AIA & 1 \\
AIA/DA & 1 \\
AIA/MA & 1 \\
AIA/RPDA & 1 \\
PIA/DA & 1 \\
PIA/MA & 1 \\
PIA/LMA & 1 \\
Three sites & $5(5)$ \\
AIA/AIA/RPDA & 1 \\
AIA/DA/PIA & 1 \\
AIA/AIA/MA & 1 \\
AIA/AIA/PIA & 1 \\
AIA/AIA/RCA & 1 \\
AIA/AIA/AIA/LMA sites & 1 \\
\hline
\end{tabular}

AIA, anterior interventricular artery; LMA, left marginal artery; DA, diagonal artery, MA, median artery; PIA, posterior interventricular artery; $\mathrm{RCA}$, right coronary artery; RPDA, right posterior diagonal artery

of trifurcation and quadrifurcation. The uncertain definition of the MA could explain these different percentages. Angelini et al. determined this artery by its distribution between the diagonal branch and left marginal artery. It may originate from the left main trunk, or proximal part of the AIA or the CxA [5], whereas some authors $[6,7,16]$ as well as ourselves defined the origin of MA as only from the left main trunk. The existence of an MA might be important as a collateral vessel in cases of AIA and CxA occlusion $[6,16]$. However, this artery could cause a problem while inserting a catheter and could lead to misdiagnosis [7].

The conal artery is an important in collateral circulation between the right and left coronary arteries [17]. It supplies the conus arteriosus and anterior, middle, and superior part of the ventricle [18]. The prevalence of this artery is reported as the first branch of RCA in $96 \%-100 \%$ $[7,10,19]$. The conal artery can originate from its own orifice in $18 \%-46.67 \%[7,17,19]$ or as a branch from the RCA in $53.34 \%-76 \%[10,17,19]$. The number of branches
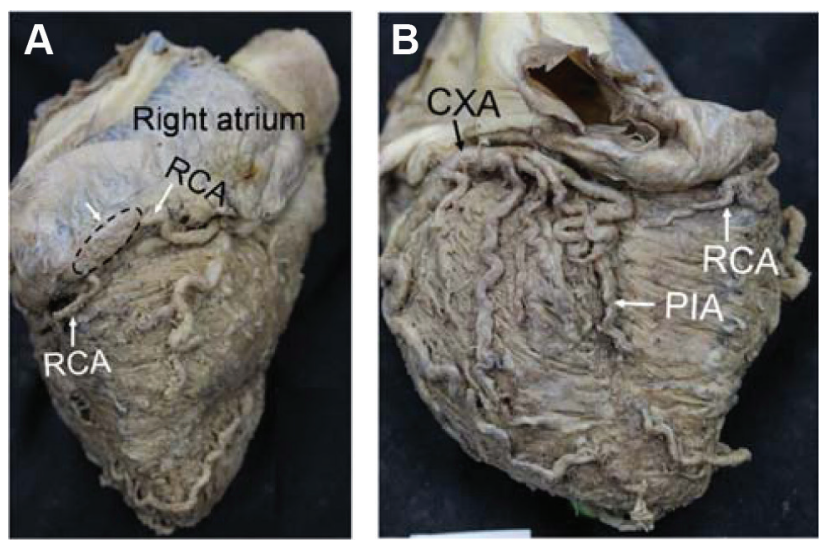

Figure 6. (A) Myocardial loop. (B) Left dominant pattern in this case. CXA, circumflex artery; PIA, posterior interventricular artery; RCA, right coronary artery

varied from 1 to $3 ; 20 \%-94 \%$ of conal arteries were observed as a single branch. The double and triple branches were reported in $1 \%-46.67 \%$ and $6.66 \%$, respectively $[17,19]$. In the present study, the prevalence and origin of conal artery were similar to those reported previously.

The artery that could be noticed before the branching of the PIA was the RPDA. This artery irrigated the inferior part of the posterior interventricular sulcus and adjacent areas. The prevalence of RPDA was $22.1 \%$ and $14 \%$ in the right dominant type $[10,20]$. The RPDA originated from the RCA in $84-86.8 \%$ and from the right marginal artery in $13.2 \%-16 \%$ $[10,20]$. Moreover, Ortale et al. reported the prevalence of this artery in all dominant circulations [11]. In the present study, there was a high percentage of RPDA and the origin in all specimens was from the RCA. The RPDA was found in both the right and codominant types.

The anomalies of coronary arteries that have hemodynamically significance are abnormalities of the origin from the opposite sinus or pulmonary artery, myocardial bridge, and coronary fistula [21]. These might be involved lifethreatening symptoms; arrhythmia, myocardial infarction, or sudden death [7]. The atypical origin of the RCA from the left sinus and from the pulmonary artery was considered to be malignantly anomalous. It has been proven that a decrease in coronary artery circulation might produce acute myocardial ischemia, arrhythmia, and sudden death [22]. This reduction in blood flow might be caused by an acute takeoff angle from the origin and the pressure effect from the interatrial course [23]. The prevalence of anomalous origin of the RCA from left sinus was observed to be $0.03-0.92 \%$ [7, 24], which was lower than that found in the present study.

The myocardial bridge comprises myocardial fibers that spread over a segment of coronary arterial branch. The bridge was determined as an atypical course that produces 

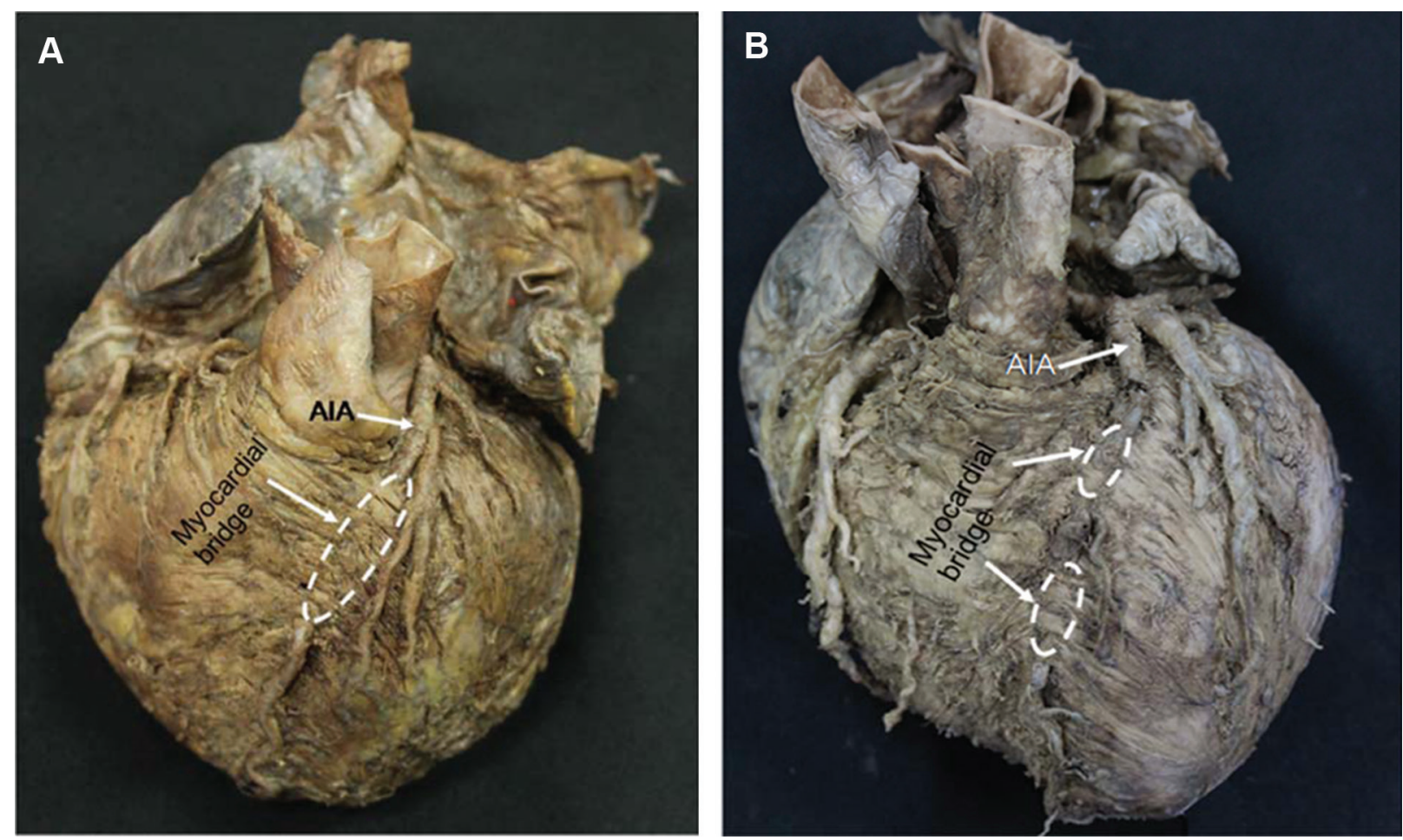

Figure 7. (A) One site of the myocardial bridge on the AIA. (B) Two sites on the AIA. AIA, anterior interventricular artery

compression of vessels during systole. Although it may be asymptomatic in most patients during a functional stress test, a myocardial bridge might be associated with atypical angina, especially in cases with a long and deep segment $[24,25]$. The prevalence of the myocardial bridge in angiography was $0.15-25 \%$ and $5-86 \%$ in autopsy reports $[6,8,24]$. Occasionally, a myocardial bridge was found at more than one site. The prevalence of single, double and triple sites of myocardial bridge were $33.33 \%, 8.30 \%$, and $3.33 \%$, respectively [26]. The middle third of the AIA followed by the left marginal artery were observed to be the most common locations $[8,15]$. In the present study, the prevalence resembled that reported at autopsy. In addition, a myocardial loop formed by the atrial myocardium on the RCA was found in one specimen. This abnormality had a minimal effect on the coronary diameter. Therefore, to our knowledge prevalence of the loop has not been mentioned in any literature [25].

\section{Conclusions}

The prevalence of right dominance, of the coronary artery, the RPDA, the atypical origin of the RCA from the left sinus and the prevalence of a myocardial bridge were found higher than that reported previously, whereas the dual aortic origin from both cusps and the prevalence of the bifurcated left main trunk were found lower than that reported previously. Therefore, physicians should be aware of variations and abnormalities of coronary arteries when inserting catheters.

Author contributions. NK and CV substantially contributed to the concept and design of the study and analyzed and interpreted the data collected substantially by NK who drafted the manuscript.VC critically revised the manuscript. Both authors approved the final version submitted for publication and take responsibility for statements made in the published article.

Acknowledgments. This study was supported by from Chulalongkorn university graduate scholarship to commemorate the 72nd anniversary of His Majesty King Bhumibol Adulyadej. The authors appreciate the contributions of medical students in dissection, Miss Sarocha Khwansang, Mr. Muhummad Chewae, and Mr. Natthawat Punyayao in the data collection procedures. We give special thanks to the technical staff of Department of Anatomy, Faculty of Medicine, Chulalongkorn University for their support in cadaveric management. The present work was presented in part as a poster at the $41 \mathrm{st}$ Annual Conference of the Anatomy Association of Thailand (AAT41), 2018 May 23-25, Cha-am, Phetchaburi, Thailand. Natatcha Khwansang, Vilai Chentanez. Anatomic variations of the coronary arteries: the origins, branching patterns and 
abnormalities [PP 31, AAT103], and as an MSc thesis submitted to the Faculty of Medicine, Chulalongkorn University, Bangkok, Thailand. Khwansang N. Anatomic variations of the coronary arteries: Thai cadaveric study. Bangkok: Chulalongkorn Univ.; 2017.

Conflict of interest statement. The authors have each completed and submitted an International Committee of Medical Journal Editors Uniform Disclosure Form for Potential Conflicts of Interest. None of the authors disclose any conflict of interest.

\section{References}

[1] World Health Organization. Cardiovascular diseases (CVDs) [online]. Geneva: World Health Organization; 2017 May 17 [cited 2018 May 01]. Available from: https://www.who.int/news-room/ fact-sheets/detail/cardiovascular-diseases-(cvds)

[2] Kiatchoosakun S, Sutra S, Thepsuthammarat K. Coronary artery disease in the Thai population: data from health situation analysis 2010. J Med Assoc Thai. 2012; 95(Suppl 7):S149-55.

[3] Nordon DG, Rodrigues O. Variations on the anatomy of the coronary arteries. J Morphol Sci. 2012; 29:178-81.

[4] Moore KL, Dalley AF, Agur AMR. Clinically oriented anatomy. 7th ed. Philadelphia: Wolters Kluwer Health/Lippincott Williams \& Wilkins; 2014.

[5] Angelini P, Velasco JA, Flamm S. Coronary anomalies: incidence, pathophysiology and clinical relevance. Circulation. 2002; 105:2449-54.

[6] Anbumani TL, Christus D, Selvi AT, Ammal SA. An anatomical study on the coronary arteries and their variations. Int J Anat Res. 2016; 4:2114-8.

[7] Koşar P, Ergun E, Öztürk C, Koşar U. Anatomic variations and anomalies of the coronary arteries: 64-slice CT angiographic appearance. Diagn Interv Radiol. 2009; 15:275-83.

[8] Beg RUM, Singh A, Goel S, Goel AK, Goel V, Goyal P, et al. Anatomical variations of coronary artery and frequency of median artery: A cadaveric study from Northern India. Int Arch Integrated Med. 2015; 2(5):88-94.

[9] Das H, Das G, Das DC, Talukdar K. A study of coronary dominance in the population of Assam. J Anat Soc India. 2010; 59:187-91.
[10] Ballesteros LE, Ramirez LM, Quintero ID. Right coronary artery anatomy: anatomical and morphometric analysis. Rev Bras Cir Cardiovasc. 2011; 26:230-7.

[11] Ortale JR, Filho JM, Paccola AMF, Leal JGPG, Scaranari CA. Anatomy of the lateral, diagonal and anterosuperior arterial branches of the left ventricle of the human heart. Braz J Cardiovasc Surg. 2005; 20:149-58. [article in English, Portuguese]

[12] Bharambe VK, Arole VU. A study of coronary dominance. Natl J Basic Med Sci. 2011; 3:178-83.

[13] Pejković B, Krajnc I, Anderhuber F. Anatomical variations of coronary ostia, aortocoronary angles and angles of division of the left coronary artery of the human heart. J Int Med Res. 2008; 36:914-22.

[14] Lufukuja GJ. Anomalous origin of the coronary arteries. Ital J Anat Embryol. 2016; 121:253-7.

[15] Vilallonga JR. Anatomical variations of the coronary arteries: I. The most frequent variations. Eur J Anat. 2003; 1:29-41.

[16] Hosapatna M, Souza AS, Prasanna LC, Bhojaraja VS, Sumalatha S. Anatomical variations in the left coronary artery and its branches. Singapore Med J. 2013; 54:49.

[17] Sankari TU, Kumar JV, Saraswathi P. The anatomy of right conus artery and its clinical significance. Recent Res Sci Technol. 2011; 3:30-9.

[18] Kurjia HZ, Chaudhry MS, Olson TR. Coronary artery variation in a native Iraqi population. Cathet Cardiovasc Diagn.1986; 12:386-90.

[19] Tomar S, Aga P, Sharma PK, Manik P, Srivastava AK. Frequency and clinical significance of conus artery and its variant third coronary artery (TCA) in North Indian population:a 64-Slice CT angiographic study. Int J Sci Res Pub. 2014; 4:1-11.

[20] Nerantzis CE, Gribizi JE, Margaris NG, Antonelis JPR, Salahas TI, Koroxenidis GT. Posterior right diagonal artery. Anat Rec. 1994; 238:528-32.

[21] Patel S. Normal and anomalous anatomy of the coronary arteries. Semin Roentgenol. 2008; 43:100-12.

[22] Ayalp R, Mavi A, Serçelik A, Batyraliev T, Gümüsburun E. Frequency in the anomalous origin of the right coronary artery with angiography in a Turkish population. Int J Cardiol. 2002; 82:253-7.

[23] Isner JM, Shen EM, Martin ET, Fortin RV. Sudden unexpected death as a result of anomalous origin of the right coronary artery from the left sinus of valsalva. Am J Med. 1984; 76:155-8.

[24] Villa AD, Sammut E, Nair A, Rajani R, Bonamini R, Chiribiri A. Coronary artery anomalies overview: the normal and the abnormal. World J Radiol. 2016; 8:537-55.

[25] Lee MS, Chen CH. Myocardial bridging: an up-to-date review. J Invasive Cardiol. 2015; 27:521-8.

[26] Ashraf YN. Myocardial bridge and coronary arteries: morphological study and clinical significance. Folia Morphol. 2014; 73:169-82. 